\title{
Women's experiences of changes in eating during pregnancy: A qualitative study in Dunedin, New Zealand
}

\author{
Helen Paterson ${ }^{A, B} B M, D T M \& H, F R A N Z C O G, M M e d S C \cdot$ E. Jean C. Hay-Smith ${ }^{B}$ PhD, MSC, Dip. \\ Physiotherapy, MPNZ - Gareth J. Treharne ${ }^{C}$ PhD, BSC (Hons), AFBPsS
}

${ }^{\mathrm{A}}$ Corresponding Author: helen. paterson@otago.ac.nz

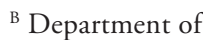
Women's and Children's Health, Dunedin School of Medicine, University of Otago, New

Zealand

${ }^{\mathrm{C}}$ Department of Psychology, University of Otago, New Zealand

\begin{abstract}
:
Background: The goal of optimal nutrition in pregnancy is to improve health outcomes for both mother and child. Healthy weight gain in pregnancy has therefore become recognised as an important aspect of perinatal care. Intuitive Eating and related 'mindful eating' have been associated with lower gestational weight gain and improved glucose control in pregnancy. Healthy weight gain in pregnancy is a current public health promotion message in New Zealand.
\end{abstract}

Objective: To explore women's experiences of eating in pregnancy, in the context of intuitive eating.

Method: This was a qualitative interview-based study of 12 purposively sampled pregnant women referred by their Lead Maternity Carer, in New Zealand. We investigated these women's perceived experiences of how their eating changed in pregnancy, specifically in the context of the phenomenon of intuitive eating. Participants were interviewed incorporating a cognitive 'think-aloud' process, whilst completing the Intuitive Eating Scale Questionnaire, followed by a semi-structured interview to discuss their experiences of eating. Themes were derived using a general inductive approach.

Findings: Four themes regarding eating during pregnancy were identified: Theme one - How women feel; Theme two - External influences; Theme three - Changed eating by choice; and Theme four Motivation to change. Changes in eating were driven by a variety of reasons which differed between women and between pregnancies. Participants described pregnancy as a time of change with regard to their experiences of eating.

Conclusion: The findings of this study support Phelan's model of pregnancy as a teachable moment for eating behaviours, which provides a potential opportunity to inform women about healthy eating.

Key words: Health behaviour, eating, weight, pregnancy, qualitative study

\section{INTRODUCTION}

Optimal nutrition in pregnancy includes: a focus on improving micronutrients vitamins and minerals; reducing risk by avoiding pathogen-contaminated foods (especially listeria); and optimising appropriate caloric intake. The goal is to improve health outcomes for both mother and child. Women's experiences of changes they may make to their eating in pregnancy are therefore important to understand and could help to provide insight into how to effect positive change (Wennberg, Lundqvist, Hogberg, Sandstrom, \& Hamberg, 2013)

Recent efforts to identify the origins of human obesity have focussed on the perinatal environment and epigenetic changes (Gluckman \& Hanson, 2008). Nutrition during pregnancy has therefore become an area of increasing interest and importance. Healthy weight gain in pregnancy has become recognised as an important aspect of perinatal care, focused around optimising wellbeing for both the mother and child. Gestational weight gain (GWG) within the 2009 United States Institute of Medicine (IOM) guidelines (Rasmussen \& Yaktine, 2009) is associated with improved outcomes including, but not limited to, lower rates of: small and large for gestation infants, maternal hypertensive disorders and childhood obesity (Kapadia et al., 2015; Oken, Taveras, Kleinman, Rich-Edwards, \& Gillman, 2007; Viswanathan et al., 2008). New Zealand has adopted these recommended GWG guidelines and healthy weight gain in pregnancy is a current public health promotion message (Ministry of Health, 2014).

Pregnancy has been recognised as a potential teachable moment with regard to a variety of health behaviours, including eating behaviours (Phelan, 2010). Teachable moments are naturally occurring life or health events that can motivate individuals to adopt risk-reducing behaviours (McBride, Emmons, \& Lipkus, 2003). Using the model described by Phelan, pregnancy might be considered an opportunity to provide advice about eating behaviours due to the presence of a number of factors, including increased emotion, increased perceived risk, increased perceived positive outcomes, and a change to social role (Phelan, 2010).

Intuitive eating (IE) is the concept of eating based on hunger and 
satiety cues rather than more emotionally based eating (Tylka, 2006). It is a specifically anti-dieting model (Gast \& Hawks, 1998). IE and related 'mindful eating' have been associated with lower GWG (Lopez-Cepero et al., 2015) and improved glucose control in pregnancy (Youngwanichsetha, Phumdoung, \& Ingkathawornwong, 2014). Investigating changes that may occur around women's eating in pregnancy and the reasons women give for these changes are necessary steps towards the development of ways to enhance behavioural changes that optimise healthy GWG and long-term health outcomes for mother and child. As part of a study of IE in pregnancy, which included the validation of the Intuitive Eating Scale (IES) (Tylka, 2006) in pregnancy (reported separately), we explored the women's experiences of eating in pregnancy in the context of intuitive eating.

\section{Intuitive eating and related 'mindful eating' have been associated with lower GWG and improved glucose control in pregnancy.}

\section{METHOD}

This was a qualitative study which used a semi-structured interview, incorporated with a 'think aloud' process during the interview, of 12 purposively selected women, designed to explore women's experiences of change in eating in pregnancy. All participants were recruited in New Zealand by midwife Lead Maternity Carers (LMCs), who are the most common primary maternity care professionals in New Zealand (New Zealand College of Midwives, 2012). The LMCs gave women an information sheet about the study and a form with which the latter could express interest in participation by returning it in a postage-paid envelope to a research assistant. The form also included a request for details of the woman's parity, gestation, weight, height, ethnicity and details about the presence or absence of nausea or vomiting. Based on responses to these questions using a sampling grid (Table 1) and a maximum variation sampling approach (Marshall, 1996), the primary researcher (HP), who is a senior lecturer and consultant obstetrician, purposively selected 12 participants in order to provide a range of BMI, parity, gestation, presence or absence of morning sickness and nausea, and to ensure representation of women identifying their ethnicity as Māori. The research assistant invited women to join the study; they were offered interview venues within the university and hospital. All the women were interviewed in the hospital. They were reimbursed for their travel and parking costs with a NZ\$50 supermarket voucher.

\section{Table 1. Sampling grid}

\begin{tabular}{|l|l|}
\hline BMI $20-25$ & BMI $>35$ \\
\hline Morning sickness yes & Morning sickness yes \\
\hline Morning sickness no & Morning sickness no \\
\hline Age $<35$ & Age $<35$ \\
\hline Age $\geq 35$ & Age $\geq 35$ \\
\hline Trimester 1st & Trimester 1st \\
\hline Trimester 2nd & Trimester 2nd \\
\hline
\end{tabular}

Interviews were carried out by HP, who had no relationship with any of the participants at the time of the interview. Written consent was obtained by HP prior to commencing the interview. Partners or support people were allowed to attend solely for the purposes of childcare. Each interview was audio recorded and lasted between
30 and 60 minutes. This period included completion of the IES (Tylka, 2006), which is a 21-item questionnaire (Table 2) on intuitive eating behaviours, using a five-point Likert scale. A cognitive 'think aloud' process was used, which involves reading aloud the instructions and questionnaire items and talking through one's thought processes in coming up with answers (Drennan, 2003). Following completion of the 'think aloud' questionnaire, there was a semi-structured interview to discuss the woman's experiences of eating (see Table 3). The semi-structured questions were collaboratively developed by the research team, which included a rehabilitation and women's health researcher (EJCHS) and a health psychology researcher (GJT) in addition to the primary researcher (HP). The aim of the interview questions was to investigate pre-pregnancy eating and establish what changes women made to their eating during pregnancy with the goal of understanding the reasons for change.

\begin{tabular}{|c|c|}
\hline \multicolumn{2}{|c|}{ Unconditional permission to eat subscale } \\
\hline Q1 & $\begin{array}{l}\text { I try to avoid certain foods high in fat, } \\
\text { carbohydrates, or calories. }\end{array}$ \\
\hline Q4 & $\begin{array}{l}\text { If I am craving a certain food, I allow myself to } \\
\text { have it. }\end{array}$ \\
\hline Q5 & $\begin{array}{l}\text { I follow eating rules or dieting plans that dictate } \\
\text { what, when, and/or how much to eat. }\end{array}$ \\
\hline Q9 & $\begin{array}{l}\text { I get mad at myself for eating something } \\
\text { unhealthy. }\end{array}$ \\
\hline Q14 & $\begin{array}{l}\text { I have forbidden foods that I don't allow myself } \\
\text { to eat. }\end{array}$ \\
\hline Q18 & $\begin{array}{l}\text { I feel guilty if I eat a certain food that is high in } \\
\text { calories, fat, or carbohydrates. }\end{array}$ \\
\hline Q19 & $\begin{array}{l}\text { I think of a certain food as "good" or "bad" } \\
\text { depending on its nutritional content. }\end{array}$ \\
\hline Q20 & I don't trust myself around fattening foods. \\
\hline Q21 & $\begin{array}{l}\text { I don't keep certain foods in my house/apartment } \\
\text { because I think that I may lose control and } \\
\text { eat them. }\end{array}$ \\
\hline \multicolumn{2}{|r|}{ Eating for physical rather than emotional reasons subscale } \\
\hline Q2 & I stop eating when I feel full (not overstuffed). \\
\hline Q3 & $\begin{array}{l}\text { I find myself eating when I'm feeling emotional } \\
\text { (e.g., anxious, depressed, sad), even when I'm not } \\
\text { physically hungry. }\end{array}$ \\
\hline Q6 & $\begin{array}{l}\text { I find myself eating when I am bored, even when } \\
\text { I'm not physically hungry. }\end{array}$ \\
\hline Q10 & $\begin{array}{l}\text { I find myself eating when I am lonely, even when } \\
\text { I'm not physically hungry. }\end{array}$ \\
\hline Q16 & $\begin{array}{l}\text { I use food to help me soothe my negative } \\
\text { emotions. }\end{array}$ \\
\hline Q17 & $\begin{array}{l}\text { I find myself eating when I am stressed out, even } \\
\text { when I'm not physically hungry. }\end{array}$ \\
\hline \multicolumn{2}{|c|}{ Reliance on internal hunger/satiety cues subscale } \\
\hline Q7 & I can tell when I'm slightly full. \\
\hline Q8 & I can tell when I'm slightly hungry. \\
\hline Q11 & I trust my body to tell me when to eat. \\
\hline Q12 & I trust my body to tell me what to eat. \\
\hline Q13 & I trust my body to tell me how much to eat. \\
\hline Q15 & When I'm eating, I can tell when I am getting full. \\
\hline
\end{tabular}




\begin{tabular}{|c|c|c|}
\hline Question & Prompts & Purpose \\
\hline $\begin{array}{l}\text { Would you please tell me about your eating } \\
\text { before you became pregnant? }\end{array}$ & $\begin{array}{l}\text { Things you enjoyed eating } \\
\text { Amounts you ate } \\
\text { When you ate } \\
\text { Who you ate with }\end{array}$ & $\begin{array}{l}\text { To establish eating behaviour prior to } \\
\text { pregnancy }\end{array}$ \\
\hline Now you are pregnant what has changed? & $\begin{array}{l}\text { Things you enjoy eating } \\
\text { Amounts you eat } \\
\text { When you eat } \\
\text { Who you eat with }\end{array}$ & $\begin{array}{l}\text { To identify changes in eating behaviour } \\
\text { which the woman associates with } \\
\text { pregnancy }\end{array}$ \\
\hline $\begin{array}{l}\text { Would you please tell me some of the } \\
\text { reasons you think these changes have } \\
\text { happened? }\end{array}$ & $\begin{array}{l}\text { Is it due to: } \\
\text { Nausea } \\
\text { Hunger / satiety (fullness) } \\
\text { Convenience } \\
\text { Advice - health professional or others } \\
\text { Other people's opinions } \\
\text { Safety - yours or your baby's? } \\
\text { "Healthiness" }\end{array}$ & $\begin{array}{l}\text { To identify ideas about why eating } \\
\text { habits change in pregnancy }\end{array}$ \\
\hline $\begin{array}{l}\text { Do you think women would find pregnancy } \\
\text { is a time when they would be motivated to } \\
\text { change their way of eating? }\end{array}$ & $\begin{array}{l}\text { For example, pregnancy has been } \\
\text { identified as a time women are } \\
\text { motivated to stop smoking. }\end{array}$ & $\begin{array}{l}\text { To establish if women think pregnancy } \\
\text { would be a time when they would be } \\
\text { motivated to change lifetime eating } \\
\text { habits }\end{array}$ \\
\hline
\end{tabular}

\begin{tabular}{|c|c|}
\hline \multicolumn{2}{|l|}{ BMI } \\
\hline $20-25$ & 5 \\
\hline $25-30$ & 2 \\
\hline$>30$ & 5 \\
\hline \multicolumn{2}{|l|}{ Age } \\
\hline$\geq 35$ & 2 \\
\hline$<35$ & 10 \\
\hline \multicolumn{2}{|l|}{ Parity } \\
\hline Nulliparous & 7 \\
\hline Multiparous & 5 \\
\hline \multicolumn{2}{|l|}{ Nausea } \\
\hline Yes & 10 \\
\hline No & 2 \\
\hline \multicolumn{2}{|l|}{ Stage of pregnancy } \\
\hline$<14$ weeks & 4 \\
\hline 14-20 weeks & 3 \\
\hline$>20$ weeks & 5 \\
\hline \multicolumn{2}{|l|}{ Ethnicity } \\
\hline NZ European & 8 \\
\hline Māori & 2 \\
\hline Samoan & 1 \\
\hline Mexican American & 1 \\
\hline
\end{tabular}

The interviews were transcribed by a professional secretary and the transcriptions were checked by an independent researcher, both of whom signed confidentiality agreements. Pauses in participants' speech were noted with ellipses (...). Round brackets were used to note details that were removed to preserve anonymity. Points of clarification were added using square brackets. Thematic analysis was performed using a general inductive approach (Thomas, 2006). Data were managed using word documents. Each interview transcript was read and responses to the 'think aloud' task and semi-structured interview questions were included within the analysis.
A case summary of each participant's interview was written by HP and reviewed with the research team to identify 'meaning units'. Subsequently, sub-themes were developed by HP and reviewed with the research team. These sub-themes were then compared by $\mathrm{HP}$ with participant responses to ensure they were representative. A final set of themes which overarched the sub-themes was reviewed with the research team and no disagreements were evident.

This study received ethics approval from the Lower South Health and Disability Ethics Committee. Ref: LRS/10/EXP/031.

\section{FINDINGS}

Using a maximal sampling approach, 13 women were directly invited to participate (to achieve the intended 12 participants) from the 26 women who expressed an interest. There were too few women with a $\mathrm{BMI}>35$ to use this as a primary sampling measure as intended (i.e., BMI $<25$ and $>35$ ). Therefore a range of BMI was selected (see Table 4). One participant's partner attended part of the interview to provide childcare, and did not contribute to the interview. The demographics of the women are shown in Table 4. Four themes regarding eating during pregnancy were identified. Changes in eating were driven by a variety of reasons which differed between women and between pregnancies.

\section{Theme one: How women feel}

Participants described changes in their eating during pregnancy due to how they felt (Table 5); this included emotional and physical feelings. Women described the effect of nausea on their eating early in pregnancy. This affected multiple facets of eating, namely hunger, choice of food, frequency of eating, and amount of food.

Participants who experienced nausea and vomiting early in pregnancy described the change from feelings of nausea to feelings of fullness as pregnancy progressed. All 12 participants, whether they experienced nausea or not, described their eating as being affected by a greater awareness of feelings of fullness during pregnancy. Other feelings described by participants were more emotional than physical. Some participants felt their eating was less driven by emotional reasons during pregnancy. This change may be because other more physical factors affect their eating 
more than emotional ones. However, pregnancy can be a time of emotional change, particularly in situations where the pregnancy was unplanned or where a mother is unsupported. The complexity around making time for cooking/eating appeared to impact on food choices. Participant two described using spare time, when she may otherwise have been bored, to prepare food. In contrast, participant eight didn't cook because she wasn't inclined to clean up.

\section{Table 5. Theme 1 - How women feel} fairly limited to kind of dry toast or... you know... those sorts of things um... and really had to make myself eat.

P10: I don't want to spend too long in your mind thinking about which food.... you feel ill yeah and you won't eat then because you just... I actually feel quite nauseated thinking about, you know, the possibility of food.

\begin{tabular}{l|l} 
Fullness & P3: I get halfway through and think, oh I
\end{tabular} can't eat any more, I have had enough. P8: I have one mouthful and then... bam I'm full!

Emotions $\quad$ P10: I find myself eating when I'm feeling emotional (e.g., anxious, depressed, sad), even when I'm not physically hungry [reading item 3 on the IES].... Um... prior to pregnancy I would agree. And haven't had the urge - it is definitely nothing to do with emotional eating when I've been pregnant.

$\mathrm{P} 1$ : But the first pregnancy was kind of hard for me because for my family to accept, because um it was out of wedlock. There was this whole emotional stress thing behind that and kind of made me yup more hungry.

Feeling of $a$ lack of time / inclination
P2: when I have the time now because pregnancy requires so much more effort, with like creating my meals and planning for lunches and things, so I think it's umm with that boredom time. Like if I don' $t$ have anything to do, I might spend more time preparing food.

P8: Like when I was bored [prior to pregnancy] I was just like yeah... I would just have something to eat, just to eat it... but now [that she is pregnant] I don't know why but like l'm just... I think it's more the fact that I can't be bothered. Like I will be bored, and I will go to the fridge and then I will be like OK I would really quite like to eat that but I would have do this and I would have to do that, and then there would be a pile of dishes at the end of it and I just can't be bothered doing that.

\section{Theme two: External influences}

Participants described external influences on their eating behaviours (Table 6) sometimes leading to behavioural change and in other situations exacerbating stress and anxiety around food choices. Participants described the impact of advice and social judgement on their eating choices; for example, participant nine was describing that she feels pressured in her food choices and acknowledging that society considers McDonald's as a safe food in contrast to smoked chicken. Women described advice they received around the safety of food choices from a variety of sources, e.g., their mother and midwife.

\begin{tabular}{|c|c|}
\hline $\begin{array}{l}\text { Cultural/ } \\
\text { social } \\
\text { pressure }\end{array}$ & $\begin{array}{l}\text { HP: You said the family were affecting } \\
\text { what you were eating. } \\
\text { P1: Yes. They just... because they knew } \\
\text { that I like fatty foods and and they } \\
\text { nagged at me so much in the first } \\
\text { pregnancy I just couldn't be bothered } \\
\text { with the whole nagging during this one, } \\
\text { because it annoyed me so much that I } \\
\text { didn't enjoy what I ate. } \\
\text { P9: Yeah. I'd hate to be like you know } \\
\text { huge big belly in } 9 \text { months and you know } \\
\text { sitting down with a lovely smoked chicken } \\
\text { sandwich or... and people going past and } \\
\text { going "ugh... look at her... she's pregnant } \\
\text { and she's eating smoked chicken!" } \\
\text { Whereas if you were rather large in your } \\
\text { pregnancy, you'd probably get away } \\
\text { with it if you were in McDonald's eating a } \\
\text { burger or at the fish and chip shop. }\end{array}$ \\
\hline $\begin{array}{l}\text { External } \\
\text { advice }\end{array}$ & $\begin{array}{l}\text { P4: Oh well just sort of my mum told me as } \\
\text { well, to stay away from seafood while you } \\
\text { are pregnant. } \\
\text { P6: because when I got so freaked out } \\
\text { about the whole milk thing, and because } \\
\text { it said about yoghurt as well... in the end } \\
\text { I was only buying one litre of milk and I } \\
\text { was just buying little things of yoghurt, so I } \\
\text { knew I could consume them within certain } \\
\text { amount of times [to reduce the listeria risk } \\
\text { due to open containers in the fridge]. } \\
\text { P9: Ummmm... I still have like breast } \\
\text { chicken, but um... don't really... well the } \\
\text { midwife told me off the last time. She said } \\
\text { what have you been eating and I said } \\
\text { ham and she went "rrr... that's naughty!" } \\
\text { So I have kind of cut the ham... I don't } \\
\text { even buy ham at the supermarket any } \\
\text { more. }\end{array}$ \\
\hline
\end{tabular}

\section{Theme three: Changed eating by choice}

Participants gave clear descriptions of changing their eating because of their knowledge and beliefs (Table 7). Some talked about how pregnancy affected their choices about food and eating, with the intent of staying healthy during pregnancy. In contrast, others described feeling it was acceptable to eat with less restraint during pregnancy. Participants described a personal concern for 
effects on the baby from potentially unsafe foods that they thus chose to avoid. Ministry of Health food safety guidelines were noted to be a source of information that were used in participants' decision making.

\section{Table 7. Theme 3 - Changed eating by choice}

\begin{tabular}{|c|c|}
\hline $\begin{array}{l}\text { Wanting } \\
\text { to stay } \\
\text { healthy in } \\
\text { pregnancy }\end{array}$ & $\begin{array}{l}\text { P1: Being pregnant and it yeah just makes } \\
\text { me aware that I take care of myself more } \\
\text { than... when I am pregnant, but when I } \\
\text { am not I just let myself go. } \\
\text { P2: Yes. But I wouldn't say I would strictly } \\
\text { avoid them [calories] but I think I would } \\
\text { lean more to the other side in terms of } \\
\text { allowing myself, especially now, to eat } \\
\text { whatever I want, rather than the you } \\
\text { might try and restrict somewhat if you're } \\
\text { um... ahh if you're not pregnant, but when } \\
\text { you are you have to eat. It's much more } \\
\text { important, you are not going to diet. }\end{array}$ \\
\hline $\begin{array}{l}\text { Choosing } \\
\text { to take } \\
\text { food safety } \\
\text { advice }\end{array}$ & $\begin{array}{l}\text { P5: like the only things that I am cutting } \\
\text { out are the things that can cause harm to } \\
\text { the baby. If it wasn't going to cause harm } \\
\text { to the baby, I would be eating it. } \\
\text { P6: those higher risk foods that we are } \\
\text { talking about in regards to the listeria } \\
\text { and things like that that they talk about } \\
\text { that can cause damage to the baby, } \\
\text { and I think, yeah... it's just... I'm more... } \\
\text { I guess I'm more aware of the fact that } \\
\text { the baby's probably more susceptible to } \\
\text { those sorts of things I think. } \\
\text { P10: You know, I have been told by a few } \\
\text { people that "oh the NZ soft cheeses are } \\
\text { fine, it's pasteurised". I am not going to } \\
\text { take the risk. It's... to me. It's on that Safety } \\
\text { Guideline. I just don't want to take the risk. }\end{array}$ \\
\hline
\end{tabular}

\section{Theme four: Motivation to change}

Participants were all specifically asked whether they thought women would find pregnancy was a time when they would be motivated to change their way of eating (Table 8). Two distinct sub-themes emerged in relation to what might motivate change in eating during pregnancy in response to this question and elsewhere in the interviews.

\section{Participants felt women would be highly motivated to change their eating if the changes would improve outcomes or reduce risk for their baby.}

Participants felt women would be highly motivated to change their eating if the changes would improve outcomes or reduce risk for their baby. The concept of pregnancy as a potential teachable moment was borne out by participants' description of women's perceived motivation to change and the opportunity to influence habits or act as a role model in the family. The timeline of pregnancy was factored into thinking about what would make change successful.
Table 8. Theme 4 - Motivation to change

For safety of P10: like even if somebody said to me that the baby "oh my gosh if you ate you know four pies in pregnancy, then it's probably going to make your baby overweight", you know, I would think "I don't want to do that". I don't want to inflict those choices upon my baby, and that... then that has no chances to change that genetic makeup or whatever, I would just completely steer clear, so... yes.

P5: Oh definitely, like the only things that I am cutting out are the things that can cause harm to the baby. If it wasn't going to cause harm to the baby, I would be eating it. Like cakes and things like that. I would definitely be eating them.

The opportunity to establish the behaviour $\mathrm{P} 1$ : and your children are a reminder of what you did when you were looking after yourself.

P6: I guess it depends how likely that change someone is to continue on [with behaviour change]. Or... it doesn't take long to start to keep those good habits so I mean, I guess nine months should be a long period of time to make a difference. P9: So I think if you got them early enough in their pregnancy, that it would become a way of life after pregnancy, so they can continue eating healthily.

\section{DISCUSSION}

The focus of this research was exploring how women changed their eating behaviours during pregnancy and whether these changes were compatible with a more intuitive style of eating. All participants described a change to eating behaviours, with the most consistent change being an increased awareness of fullness. Although fullness was a specific question on the IES, most women explored the issue further with descriptions of their degree of awareness, thus fullness was the clearest of all sub-themes identified. This is an interesting finding and suggests that pregnancy may be a useful time to teach women about the sensation of satiety, a component of IE, which could feasibly lead to higher levels of IE postpartum.

\section{All participants described a change to eating behaviours, with the most consistent change being an increased awareness of fullness.}

The results of our study were considered within the context of the factors described by Phelan as a necessary part of the 'teachable moment' as applied to pregnancy (Phelan, 2010). We identified themes which fit the Phelan model (Figure 1), suggesting that pregnancy is a teachable moment and women are more likely to change to health-supporting behaviour. 


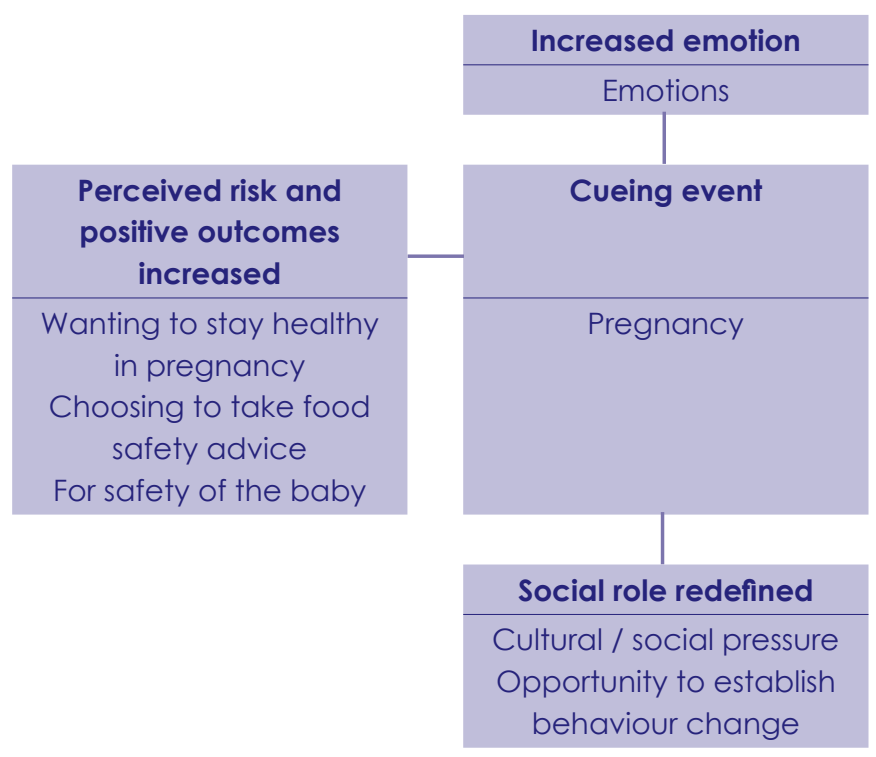

Figure 1. Themes identified within Phelan's model of a teachable moment

Women recognised pregnancy and breastfeeding to be a special time when women may be motivated to change eating behaviours, mostly for the wellbeing of their babies, and they acknowledged that this time was long enough to establish a sustainable change. For example, one participant noted: “... it doesn't take long to start to keep those good habits so I mean, I guess nine months should be a long period of time to make a difference."

\section{Women recognised pregnancy and breastfeeding to be a special time when women may be motivated to change eating behaviours, mostly for the wellbeing of their babies, and they acknowledged that this time was long enough to establish a sustainable change.}

The World Health Organization describes a doubling of the prevalence of obesity in the world since the 1980s; to reduce this increase effective interventions are required (World Health Organization, 2011). The evidence that the perinatal environment impacts on obesity in the child means that interventions should be focused pre-conceptually (Gluckman \& Hanson, 2008). However, around $40 \%$ of pregnancies are unplanned so a large proportion of women are unlikely to have adapted their eating behaviour prepregnancy (Morton et al., 2012). Whilst our study found that women changed their eating behaviour during pregnancy, there is still further work necessary to optimise healthy nutrition in the perinatal period. The sub-theme 2.1 - Cultural/social pressure - suggests women change their behaviour due to societal views. Until societal pressures on women are focused on healthier eating rather than some of the negative risk avoidance aspects presently described in Sub-theme 2.2 - External advice - it may be hard for women to choose the moderate risk of listeria in a smoked chicken sandwich over the high fat McDonald's meal described by one participant.
Diet is presently considered the most effective mechanism for optimising healthy gestational weight gain (Muktabhant, Lawrie, Lumbiganon, \& Laopaiboon, 2015; Thangaratinam et al., 2012). Studies show high levels of GWG in excess of recommendations (Chung et al., 2013; Dodd et al., 2014). In view of the increasing epidemic of obesity and the potential positive effect of the perinatal environment on long-term risk of obesity, we wonder whether it is time to support a different approach to nutrition; one which promotes healthy choices rather than avoidance of certain foods. Additionally, we have demonstrated that pregnancy is a 'teachable moment' and suggest that this is a time when health professionals could be supporting and endorsing changes to eating behaviours.

\section{STRENGTHS AND LIMITATIONS}

There is the potential for a recruitment bias when recruiting participants to a study related to weight due to the sensitivity of the issue. However, the qualitative nature of the study and the purposive sampling enabled a wide range of participant demographics to be included. Further research is required to generalise these results on a population basis. Participants were New Zealand women under the care of midwifery LMCs. This study adds to the NZ literature on women's views of dietary changes in pregnancy.

\section{CONCLUSION}

Participants described pregnancy as a time of change with regards to their experiences of eating; particularly an increase in satiety. The findings of this study support Phelan's model of pregnancy as a teachable moment for eating behaviours (Phelan, 2010), which provides a potential opportunity to inform women about healthy eating. Changes in eating behaviours identified were consistent with the potential use of IE as a mechanism to improve levels of healthy GWG. However, further investigation of IE in pregnancy is necessary to establish the relationship between IE in pregnancy and GWG.

\section{ACKNOWLEDGEMENTS}

We would like to thank the participants and the Lead Maternity Carers who recruited them for this research. The authors would also like to acknowledge the contribution of Dr Caroline Horwath and Prof. Peter Herbison to the study design and Gaye Ellis, research assistant, for her support. This study was funded by a University of Otago Research Grant. The authors declare there is no conflict of interest.

\section{REFERENCES}

Chung, J. G., Taylor, R. S., Thompson, J. M., Anderson, N. H., Dekker, G. A., Kenny, L. C., \& McCowan, L. M. (2013). Gestational weight gain and adverse pregnancy outcomes in a nulliparous cohort. European Journal of Obstetrics \& Gynecology and Reproductive Biology, 167(2), 149-153. doi:10.1016/j.ejogrb.2012.11.020

Dodd, J. M., Turnbull, D., McPhee, A. J., Deussen, A. R., Grivell, R. M., Yelland, L. N., for the Limit Randomised Trial Group. (2014). Antenatal lifestyle advice for women who are overweight or obese: LIMIT randomised trial. BMJ, 348, g1285. doi:10.1136/bmj.g1285

Drennan, J. (2003). Cognitive interviewing: verbal data in the design and pretesting of questionnaires. Journal of Advanced Nursing, 42(1), 57-63. doi:10.1046/j.1365-2648.2003.02579.x

Gast, J., \& Hawks, S. R. (1998). Weight loss education: the challenge of a new paradigm. Health Education \& Behavior, 25(4), 464-473. Retrieved from http://heb.sagepub.com/content/25/4/464.full.pdf+html

Gluckman, P. D., \& Hanson, M. A. (2008). Developmental and epigenetic pathways to obesity: an evolutionary-developmental perspective. International Journal of Obesity, 32(S7), S62-71. doi:10.1038/ ijo.2008.240

Kapadia, M. Z., Park, C. K., Beyene, J., Giglia, L., Maxwell, C., \& McDonald, S. D. (2015). Can we safely recommend gestational weight 
gain below the 2009 guidelines in obese women? A systematic review and meta-analysis. Obesity Reviews, 16(3), 189-206. doi:10.1111/obr.12238

Lopez-Cepero, A., Leung, K., Corvera, S., Moore, T., \& Rosal, M. (2015). Impact of Eating Behaviors and Cravings on Gestational Weight Gain and Diet. The FASEB Journal, 29(1 Supplement). Retrieved from http://www.fasebj.org/content/29/1_Supplement/900.19.abstract

Marshall, M. N. (1996). Sampling for qualitative research. Family Practice, 13(6), 522-526. doi:10.1093/fampra/13.6.522

McBride, C. M., Emmons, K. M., \& Lipkus, I. M. (2003).

Understanding the potential of teachable moments: the case of smoking cessation. Health Education Research, 18(2), 156-170. Retrieved from http://her.oxfordjournals.org/content/18/2/156.full.pdf

Ministry of Health. (2014). Guidance for Healthy Weight Gain in Pregnancy. Wellington: Ministry of Health.

Morton, S., Carr Atatoa, P. E., Grant, C., Robinson, E. M., Bandara, D. K., Bird, A., . . W Wall, C. (2012). Cohort Profile: Growing Up in New Zealand. International Journal of Epidemiology, 1-11. doi:10.1093/ije/ dyr206

Muktabhant, B., Lawrie, T. A., Lumbiganon, P., \& Laopaiboon, M. (2015). Diet or exercise, or both, for preventing excessive weight gain in pregnancy. The Cochrane Database of Systematic Reviews, 6, CD007145. doi:10.1002/14651858.CD007145.pub3

New Zealand College of Midwives. (2012). About lead maternity carer (LMC) provided services. Retrieved from http://www.midwife.org.nz/ index.cfm/1,133, html

Oken, E., Taveras, E. M., Kleinman, K. P., Rich-Edwards, J. W., \& Gillman, M. W. (2007). Gestational weight gain and child adiposity at age 3 years. American Journal of Obstetrics and Gynecology, 196(4), 322. e321-328. doi:10.1016/j.ajog.2006.11.027

Phelan, S. (2010). Pregnancy: a "teachable moment" for weight control and obesity prevention. American Journal of Obstetrics and Gynecology, 202(2), 135.e131-135.e138. Retrieved from http://www.sciencedirect. com/science/article/B6W9P -4X0W4RW-4/2/956b8181c833c26ded376 dbfa0bfe2ba

Rasmussen, K. M., \& Yaktine, A. L. (2009). Weight Gain During Pregnancy: Reexamining the Guidelines. In National Academy of Sciences (US) (Ed.), The National Academies Collection: Reports funded by National Institutes of Health. Washington (DC): National Academies Press (US).

Thangaratinam, S., Rogozinska, E., Jolly, K., Glinkowski, S., Roseboom, T., Tomlinson, J. W., Khan, K. S. (2012). Effects of interventions in pregnancy on maternal weight and obstetric outcomes: meta-analysis of randomised evidence. BMJ, 344, e2088. doi:10.1136/bmj.e2088

Thomas, D. R. (2006). A General Inductive Approach for Analyzing Qualitative Evaluation Data. American Journal of Evaluation, June 2006(27), 237-246. doi:10.1177/1098214005283748

Tylka, T. L. (2006). Development and psychometric evaluation of a measure of intuitive eating. Journal of Counseling Psychology, 53(2), 226-240.

Viswanathan, M., Siega-Riz, A. M., Moos, M. K., Deierlein, A., Mumford, S., Knaack, J., . . . Lohr, K. N. (2008). Outcomes of maternal weight gain. Evidence Reports/Technology Assessments (Full Report)(168), $1-223$.

Wennberg, A. L., Lundqvist, A., Hogberg, U., Sandstrom, H., \& Hamberg, K. (2013). Women's experiences of dietary advice and dietary changes during pregnancy. Midwifery, 29(9), 1027-1034. doi:10.1016/j. midw.2012.09.005

World Health Organization. (2011). Obesity and overweight. Retrieved from http://www.who.int/mediacentre/factsheets/fs311/en/index.html. (Fact sheet No311). Retrieved 7 June 2011, World Health Organization http://www.who.int/mediacentre/factsheets/fs311/en/index.html\#

Youngwanichsetha, S., Phumdoung, S., \& Ingkathawornwong, T. (2014). The effects of mindfulness eating and yoga exercise on blood sugar levels of pregnant women with gestational diabetes mellitus. Applied Nursing Research, 27(4), 227-230. doi:10.1016/j.apnr.2014.02.002

\section{Accepted for publication February 2016}

Paterson, H., Hay-Smith, E., Treharne, G. (2016). Women's experiences of changes in eating during pregnancy: A qualitative study in Dunedin, New Zealand. New Zealand College of Midwives Journal 52, 5-11.

http://dx.doi.org/10.12784/nzcomjnl52.2016.1.5-11

\section{Would you like to publish in the Journal?}

Share your knowledge, experiences and research with your New Zealand and International colleceyes:

If you are in postgraduate study or undertaking a research project we would like to hear from you - email: practice@nzcom.org.nz or visit www.midwife.org.nz/ resources-events/nzcomjournal for more information

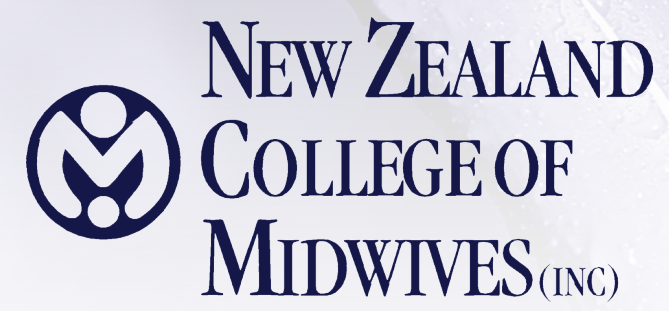

